\title{
BMJ Open SecurAstaP trial: securement with SecurAcath versus StatLock for peripherally inserted central catheters, a randomised open trial
}

Godelieve Alice Goossens, ${ }^{1,2}$ Niel Grumiaux, ${ }^{3}$ Christel Janssens, ${ }^{1}$ Martine Jérôme, ${ }^{1}$ Steffen Fieuws, ${ }^{4}$ Philip Moons, ${ }^{2,5}$ Marguerite Stas, ${ }^{6}$ Geert Maleux ${ }^{7}$

To cite: Goossens GA, Grumiaux N, Janssens C, et al. SecurAstaP trial: securement with SecurAcath versus StatLock for peripherally inserted central catheters, a randomised open trial. BMJ Open 2018;8:e016058. doi:10.1136/ bmjopen-2017-016058

- Prepublication history and additional material for this paper are available online. To view these files, please visit the journal online (http://dx.doi org/10.1136/bmjopen-2017016058).

Received 24 January 2017 Revised 22 November 2017 Accepted 12 December 2017

Check for updates

For numbered affiliations see end of article.

\section{Correspondence to} Dr Godelieve Alice Goossens; Godelieve.Goossens@uzleuven. be

\section{ABSTRACT}

Objectives To assess the effect on needed nursing time for dressing change.

Design, setting, participants A parallel-group, openlabel, randomised controlled trial in patients who are in need for a peripherally inserted central catheter insertion in one teaching hospital in Belgium. The follow-up lasted 180 days or until catheter removal, whatever came first. A computer generated table was used to allocate devices. Randomised patients were 105 adults (StatLock, $n=53$; SecurAcath, $n=52$ ) and primary analysis was based on all patients $(n=92)$ with time measurements (StatLock, $n=43$; SecurAcath, $n=49$ ).

Interventions StatLock which has to be changed weekly versus SecurAcath which could remain in place for the complete catheter dwell time.

Main outcome measure Needed time for the dressing change at each dressing change (SecurAcath) or at each dressing change combined with the change of the securement device (StatLock).

Results Median time needed for dressing change was $7.3 \mathrm{~min}$ ( $95 \% \mathrm{Cl} 6.4 \mathrm{~min}$ to $8.3 \mathrm{~min}$ ) in the StatLock group and in the SecurAcath group $4.3 \mathrm{~min}(95 \% \mathrm{Cl} 3.8 \mathrm{~min}$ to $4.9 \mathrm{~min})(\mathrm{P}<0.0001)$. The time in the SecurAcath group was reduced with $41 \%$ (95\% $\mathrm{Cl} 29 \%$ to $51 \%)$. Incidence rates of migration, dislodgement and catheter-related bloodstream infection were comparable across groups. Pain scores were higher with SecurAcath than with StatLock at insertion $(P=0.02)$ and at removal $(P<0.001)$ and comparable during dressing change $(\mathrm{P}=0.38)$ and during dwell time $(P=0.995)$. User-friendliness was scored at insertion and removal. All statements regarding the user-friendliness were scored significantly higher for StatLock than for SecurAcath $(P<0.05)$. Only for the statement regarding the recommending routine use of the device, which was asked at removal, no difference was found between the two devices $(P=0.32)$.

Conclusion Use of SecurAcath saves time during dressing change compared with StatLock. Training on correct placement and removal of SecurAcath is critical to minimise pain. Trial registration number NCT02311127; Pre-results.

\section{INTRODUCTION}

Peripherally inserted central catheters (PICCs) are mainly used for the
Strengths and limitations of this study

- Nursing procedural time as primary outcome measurement which is key when staff nurses are involved in device care on a regularly basis.

- Multiprofessional conducted trial which evaluated needed time for care, clinical outcomes and also usability data from device inserters, device users and patients.

- First randomised controlled trial with SecurAcath versus StatLock with rigorous trial methodology to enhance reliability of results despite securement devices is not amenable to blinding.

- Full economic assessment of the use of both securement devices is lacking.

administration of intravenous fluids, drugs and for blood sampling. PICCs may remain in place for months and therefore may be considered mid to long-term central venous access devices. However, PICCs tend to be non-cuffed and thus at higher risk of movement, migration and total dislodgement. Consequences related to these complications include bacterial migration and catheter-related bloodstream infection (CRBSI), venous thrombosis, treatment delay and catheter replacement. ${ }^{1}$ Therefore adequate securement is critical during the complete PICC dwell time. Several securement and dressing products are available. ${ }^{2}$ However, catheters with securement systems that need to be regularly changed might be prone to dislodgement because the catheter is freefloating during securement device changes. Moreover, these adhesive-based devices may lead to medical adhesive-related skin injury (MARSI). ${ }^{3}$ A subcutaneous catheter securement system could overcome these two disadvantages: by not requiring removal until the end of treatment and not requiring adhesive securement to skin. In addition, unlike the 
adhesive securement device, the subcutaneous device does not need changing, therefore the time needed for the exit site care will be shortened. Declining hospital reimbursement and nursing shortages reduces the time available for bedside nurses to complete care activities. ${ }^{4}$ Therefore, new technologies should be critically evaluated for their added value in patient care and also their impact on nursing care activities. We conducted a randomised controlled trial (RCT) to compare an adhesive-backed anchor pad with a subcutaneous catheter securement system for PICCs. The objective of this study was to determine differences in nursing time for dressing change. We also investigated complications and experiences of the healthcare worker and the patient with the securement device at PICC insertion during dressing change and at PICC removal.

\section{MATERIALS AND METHODS \\ Study design}

This investigator-driven study is a single-centre, parallel-group and open-label, RCT. Patients were recruited in the university hospitals Leuven, Belgium, where a team of interventional radiologists insert approximately 1000 PICCs per year. Advanced practice nurses (APN) from the vascular access team are responsible for development of procedures, staff education, research and troubleshooting in case of PICC-related problems. Patients were recruited between April 2015 and August 2015. Follow-up lasted until December 2015. Eligible patients were over 18 years old and scheduled for a PICC insertion with a polyurethane catheter, had a planned follow-up in the study centre and were able to speak and understand Dutch. Patients were excluded if they were unable to sign an informed consent form (ICF) and if they had a known allergy to nickel and/or ethylene oxide. All patients scheduled for PICC insertion in the IR suite were screened by a member of the research team for eligibility. Patients were recruited by the same team at a hospital ward or in rare occasions in the waiting room of the IR suite. Written informed consent was obtained before PICC insertion.

\section{Outcomes and procedures}

Our primary outcome measure was the time needed for the dressing change. We chose this endpoint because we hypothesised that the procedural time will be reduced if there is no need for a change of the securement device during dressing change. Moreover, we anticipated that the reduction in stress experienced by the nurse due to decreased risk of catheter dislodgement would also contribute to decrease the time taken to change the dressing. Ward nurses measured the time taken for the dressing change at each dressing change (SecurAcath group) or at each dressing change combined with the change of the securement device (StatLock group). They used the clock in the patient room or a watch on a cell phone. The time was recorded in minutes starting from the moment that all material was prepared just before

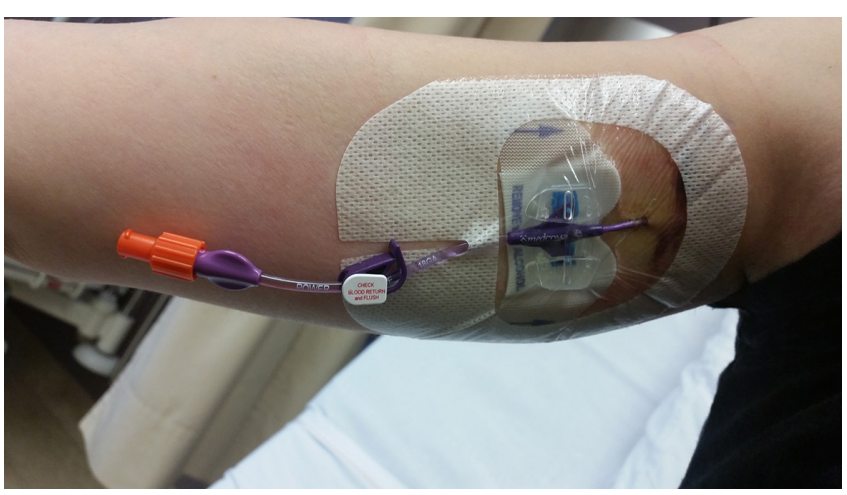

Figure 1 PICC secured with StatLock ${ }^{\circledR}$. PICC, peripherally inserted central catheter.

the removal of the catheter dressing until the end of the procedure with the application of the new catheter dressing. In both groups, similar types of catheter dressing were used. At insertion, a gauze dressing, (Cosmopor E, Hartmann) which has to be changed within 24 hours, was applied thereafter a transparent semipermeable membrane (TSM) dressing (Tegaderm 3M) was used. The TSM dressing was always placed over the StatLock (figure 1) and SecurAcath (figure 2). In case of signs of exit site infection, a Biopatch (Johnson \& Johnson) was applied. Cavilon (3M) was used in case of skin irritation.

We selected the following assessments as secondary outcomes: (1) catheter migration at dressing change, (2) catheter dislodgement resulting in premature PICC removal, (3) CRBSI, (4) patient's pain and (5) usability of the securement devices.

At the initiation of SecurAcath in the hospital, 6 months before study start, inserters followed a formal training on the placement of SecurAcath and also the APN of the vascular access team were trained for device removal. The first 70 patients with a PICC secured with SecurAcath were followed closely to monitor problems and complications with the devices, including optimising placement and removal technique. These trained interventional radiologists inserted Bard PowerPICCs (C.R. Bard, Salt Lake, Utah, USA) and they completed a case report form containing the indication for insertion, PICC

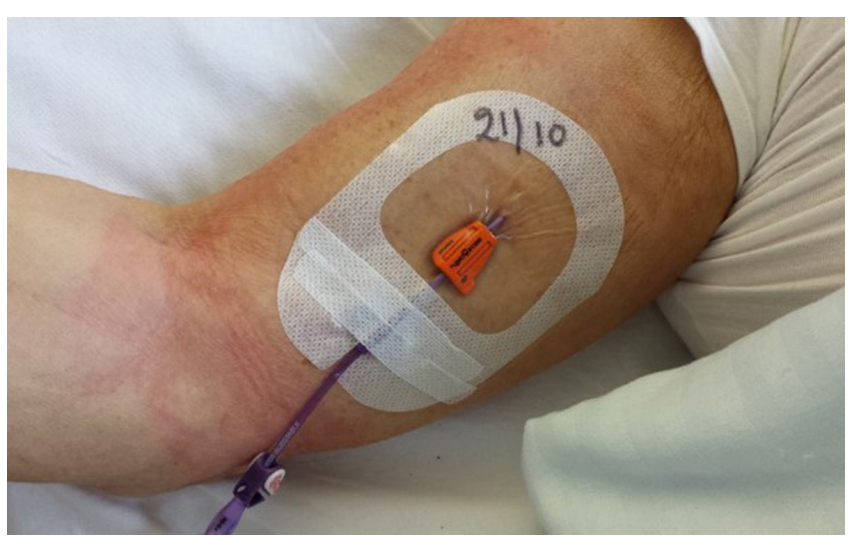

Figure 2 PICC secured with SecurAcath ${ }^{\circledR}$. PICC, peripherally inserted central catheter. 
details and periprocedural problems. The experience of the radiologists who placed and, nurses and physicians who removed the securement device, was assessed on a categorical level (no experience, $<10$ and $\geq 10$ times). APN from the vascular access team removed the SecurAcath. The usability of the securement device was evaluated at PICC insertion and a second time at removal by scoring four statements (self-developed, close-ended statements with a five-item Likert-type scale). Patients were asked if they had previously had a PICC inserted and which securement device was used.

Patients reported pain on a Numerical Rating Scale (NRS) from 0 (no pain) to 10 (worst pain possible) at securement placement, at each dressing change, at removal for the evaluation of the removal procedure and also the complete catheter dwell time.

At dressing change, nurses described their own level of experience with the specific securement device (no experience, $<10$ handlings and $\geq 10$ handlings). At every dressing change, the external catheter length was measured to document eventual catheter migration. The external length was defined as zero when the zero mark sign of the first bullet marked on the PICC was at exit site for the StatLock and for the SecurAcath, if the zero mark sign was visible just behind the SecurAcath device, or in other words $3 \mathrm{~cm}$ from the exit site. Migration was defined as an accidental partial slip out of the PICC with an external catheter length of $\geq 3 \mathrm{~cm}$ from the zero mark, while the PICC could be used further. We opt to define migration as a $3 \mathrm{~cm}$ supplementary external movement of the catheter because this is a substantial slip out of the catheter which could lead to loss of venous access.

At PICC removal, the reason for removal was recorded. Catheter dislodgement was defined as the accidental partial or total catheter slip out resulting in loss of the PICC. CRBSI was studied retrospectively by reviewing all microbial cultures available in the hospital information system. We defined laboratory-confirmed CRBSI as the presence of positive blood cultures from both the PICC and peripheral veins with the same pathogen and fever or chills in the absence of other infection sources. ${ }^{5}$ Furthermore, specific removal data were collected: complications during removal if any, and, in the SecurAcath group, the use of any local anaesthesia and technique of removal (cutting the device before removal or not). Patients were asked whether they would choose the same type of securement device if needed in the future (yes/no). All data were recorded on specially designed forms. Patients were followed for a maximum of 180 days or until catheter removal, whatever came first.

\section{Calculation of the sample size}

We expected less time for dressing change in the SecurAcath group compared with the StatLock group. We presumed, based on our observations, a time reduction of $30 \%$ for the dressing change in the SecurAcath group due to the omission of the time spent to remove and to apply a new StatLock. Based on a two-sided two-sample pooled t-test of a mean ratio with lognormal data, 102 subjects in total were needed to have $80 \%$ power (with $\alpha$ set at $5 \%$ ) to detect a $30 \%$ reduction in time needed, assuming a coefficient of variation (ratio of SD vs the mean) equal to 0.7 . The sample size calculation was performed under the worst case scenario that only a single measurement would be available per patient.

\section{Randomisation and masking}

We randomly assigned patients in a 1:1 ratio following a simple randomisation procedure (computerised random numbers) to two groups: the StatLock adhesive device (C.R. Bard) or the SecurAcath subcutaneous device (Interrad Medical, Plymouth, Minnesota, USA). In the StatLock group, the securement device together with the catheter dressing, was changed weekly or earlier if loose, wet or soiled. In the SecurAcath group, the securement system remained in place for the complete catheter dwell time while the catheter dressing was changed weekly or earlier if loose, wet or soiled. The allocation sequence was concealed from researchers who enrolled patients according to sequentially numbered opaque sealed envelopes which contained a card with the group assignment. The allocation concealment method was maintained, without problem. Neither patients nor assessors could be blinded because the devices were externally visible and obviously different.

\section{Statistical analysis}

A linear mixed model with a random subject effect to handle the multiple observations per subject was used to compare the time needed for the dressing change between both groups. The analysis was performed on log-transformed time values. In both groups, geometric means, their ratio and $95 \%$ CIs that are obtained after backtransforming to the original scale are reported. All patients with measurements were included in the analysis. Analysis is carried out using the SAS software, V.9.2 (SAS, Cary, North Carolina, USA). Secondary outcomes are analysed using SPSSV.19 (IBM Statistics SPSS, Chicago, Illinois, USA). The following agreement levels on the statements about the securement device for the Likert scores are used: 1: strongly disagree; 2: disagree; 3: neutral; 4: agree; 5 : strongly agree. Results of the NRS pain scores are categorised to none (0), mild (1-2-3), moderate (4-5-6) and severe (7-8-9-10). Nominal and ordinal data were expressed in absolute numbers and percentages, and continuous data were expressed in mean and SD (medians and quartiles when required). The proportion of dressing changes with a reported clinical problem was compared between both groups using a logistic regression model with generalised estimating equations (GEE) based on an independent working correlation matrix to handle the correlation between the multiple dressing changes within the same patient. Given the low number of events for most specific problems, no statistical tests correcting for the within-patient correlation were reported for these. Comparisons of ordinal 


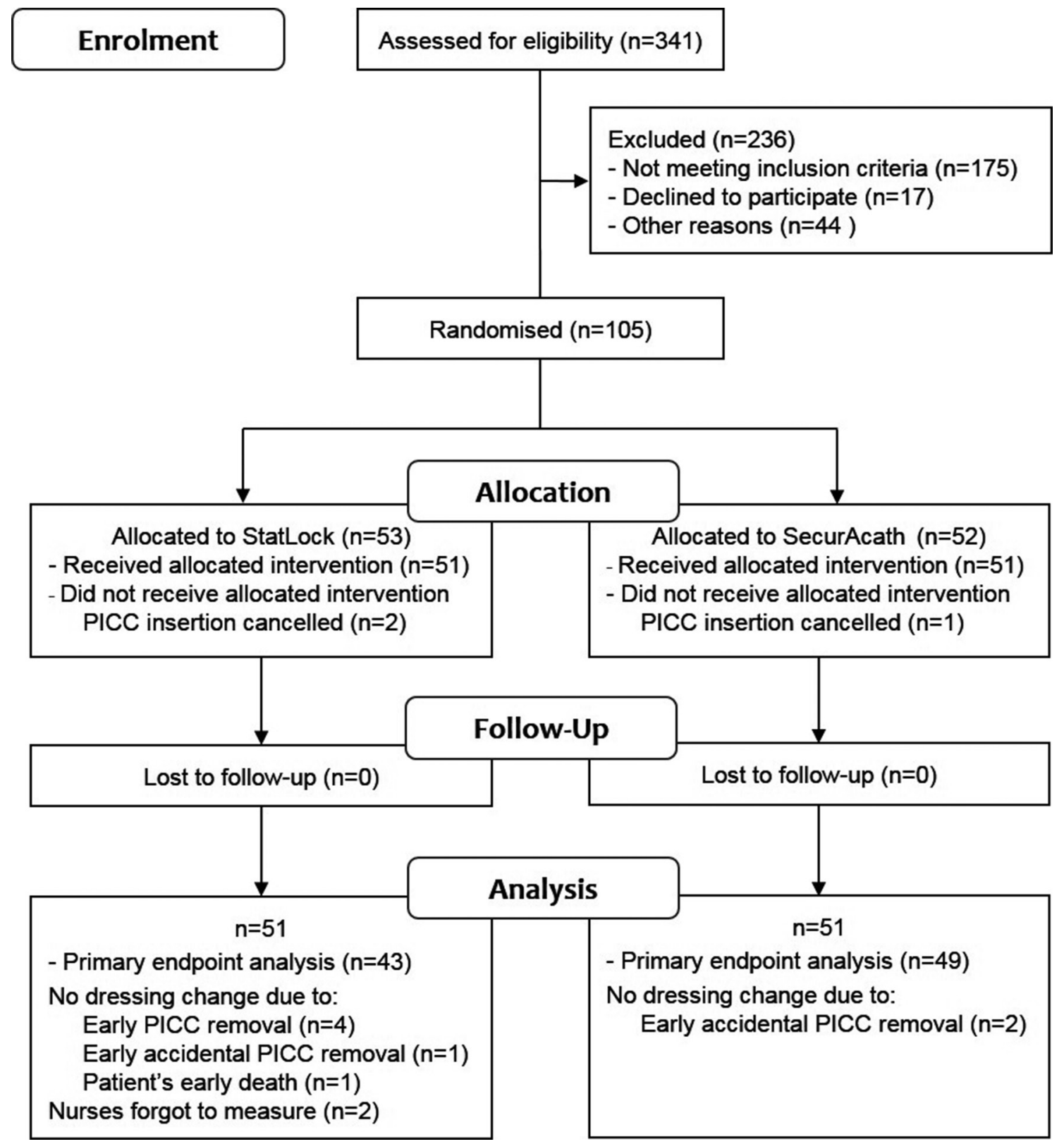

Figure 3 Patient flow. PICC, peripherally inserted central catheter.

variables were performed by Mann-Whitney $\mathrm{U}$ tests and Fisher's exact test was used to compare proportions. All tests were two-sided and $\mathrm{P}$ values smaller than 0.05 were considered significant.

\section{RESULTS}

\section{Patient and device characteristics}

We assessed 341 patients for eligibility; 105 met the inclusion criteria. After randomisation, 53 patients were allocated to receive a StatLock and 52 a SecurAcath. PICC insertion was cancelled in three patients. No patients were lost to follow-up. No reports of measurements of the dressing change procedure were available for 10 patients, 8 in the StatLock and 2 in the SecurAcath group. The main reason for the missing data was that no dressing changes are done due to the short PICC dwell time. Figure 3 shows the patients' flow. For the primary outcome analysis, we have data on 43 patients in the StatLock group and 49 in the SecurAcath group. For the secondary outcomes, the 51 patients per group were taken into account; however, the completeness of the data is varying along the different variables. Therefore, in the tables, in the corresponding row, the total number of patients and/or measurements is shown per variable. The two groups were comparable in terms of patient and PICC characteristics (table 1). The most frequent indication for PICC insertion was the administration of intravenous antibiotic therapy. The median number of catheter days was 16 days $(\mathrm{Q} 1=10$ days; $\mathrm{Q}=38$ days) in the StatLock group and 21 days $(\mathrm{Q} 1=11$ days; $\mathrm{Q} 3=41$ days $)$ in the SecurAcath group. At least one PICC had previously been inserted in 16 patients (31.4\%) in the StatLock group and 
Table 1 Patient and PICC characteristics and healthcare worker's level of experience with the securement device

\begin{tabular}{|c|c|c|}
\hline & $\begin{array}{l}\text { StatLock } \\
(n=53)\end{array}$ & $\begin{array}{l}\text { SecurAcath } \\
(n=52)\end{array}$ \\
\hline \multicolumn{3}{|l|}{ Sex } \\
\hline Females, n (\%) & $29(54.7)$ & $21(40.4)$ \\
\hline Median age in years (Q1-Q3) & $62(51-69)$ & $64(50-71)$ \\
\hline Reason for PICC insertion & $\mathrm{n}(\%)$ & $\mathrm{n}(\%)$ \\
\hline Antibiotic therapy & $26(49.1)$ & $26(50.0)$ \\
\hline Supportive care & $18(34.0)$ & $13(25.0)$ \\
\hline Chemotherapy & $9(17.0)$ & $11(21.2)$ \\
\hline Other & $0(0.0)$ & $2(3.8)$ \\
\hline PICC diameter & $\mathrm{n}(\%)$ & $\mathrm{n}(\%)$ \\
\hline $4 \mathrm{FR}$ (single lumen) & 49 (92.5) & $46(88.5)$ \\
\hline 5 FR (double lumen) & $2(3.8)$ & $5(9.6)$ \\
\hline Insertion cancelled & $2(3.8)$ & $1(1.9)$ \\
\hline External length in $\mathrm{cm}$ at insertion & $\mathrm{n}=51$ & $\mathrm{n}=50$ \\
\hline Mean (SD) & $0.1(0.6)$ & $0.5(0.9)$ \\
\hline Min-max & $-1^{*}$ to 2 & $0-2$ \\
\hline $\begin{array}{l}\text { Difference in external length in cm } \\
\text { (at dressing change compared with } \\
\text { insertion) }\end{array}$ & $n=134$ & $\mathrm{n}=115$ \\
\hline Mean (SD) & $0.2(0.8)$ & $0.1(2.0)$ \\
\hline Min-max & -2 to 5 & -2 to 18 \\
\hline $\begin{array}{l}\text { Number of catheter days (catheter } \\
\text { dwell time) }\end{array}$ & $\mathrm{n}=51$ & $\mathrm{n}=51$ \\
\hline Total number & 1541 & 1572 \\
\hline Median (Q1-Q3) & $16(10-38)$ & $21(11-41)$ \\
\hline Min-max & $1-179$ & $1-180$ \\
\hline $\begin{array}{l}\text { Radiologist's experience with } \\
\text { securement device at insertion }\end{array}$ & $\begin{array}{l}\mathrm{n}=42 \\
\mathrm{n}(\%)\end{array}$ & $\begin{array}{l}\mathrm{n}=42 \\
\mathrm{n}(\%)\end{array}$ \\
\hline First time user & $1(2.4)$ & $4(9.5)$ \\
\hline$<10$ times & $4(9.5)$ & 7 (16.7) \\
\hline$\geq 10$ times & 37 (88.1) & $31(73.8)$ \\
\hline $\begin{array}{l}\text { Nurse's experience with securement } \\
\text { device at dressing change }\end{array}$ & $\begin{array}{l}\mathrm{n}=156 \\
\mathrm{n}(\%)\end{array}$ & $\begin{array}{l}\mathrm{n}=159 \\
\mathrm{n}(\%)\end{array}$ \\
\hline No experience & $23(14.7)$ & $67(42.2)$ \\
\hline$<10$ times & $59(37.8)$ & $69(43.4)$ \\
\hline$\geq 10$ times & 74 (47.4) & $23(14.5)$ \\
\hline $\begin{array}{l}\text { Experience with securement device at } \\
\text { removal }\end{array}$ & $\begin{array}{l}\mathrm{n}=31 \\
\mathrm{n}(\%)\end{array}$ & $\begin{array}{l}\mathrm{n}=43 \\
\mathrm{n}(\%)\end{array}$ \\
\hline First time user & $2(6.5)$ & 7 (16.3) \\
\hline$<10$ times & 7 (22.6) & 7 (16.3) \\
\hline$\geq 10$ times & $22(71)$ & $29(67.4)$ \\
\hline
\end{tabular}

* $-1 \mathrm{~cm}$ was noted when the PICC was inserted until the thickening (of the PICC's wings) which resulted in an invisible 'zero' mark sign on the PICC at the exit site.

PICC, peripherally inserted central catheter.

in 17 patients (33.3\%) in the SecurAcath group. Of these, one patient in the SecurAcath group and three patients in the StatLock group confirmed that they have had the PICC secured with a SecurAcath in the past. At insertion, most radiologists had some experience with securement device placement and used it previously $\geq 10$ times in 37 $(88.1 \%)$ and in $31(73.8 \%)$ cases in the StatLock group and in the SecurAcath group, respectively. No procedural complications were reported. In 22 of the 31 evaluations $(71.0 \%)$ in the StatLock group and 29 of the 43 evaluations $(67.3 \%)$ in the SecurAcath group, healthcare workers who removed the PICC with securement device were experienced and removed the device already $\geq 10$ times.

\section{Time needed for dressing change}

Time was measured during 325 dressing changes with 161 in the StatLock group and 164 in the SecurAcath group with a mean number of 3.74 measurements (SD 3.48) with a median of 3 measurements $(\mathrm{Q} 1=2 ; \mathrm{Q} 3=6)$ and 3.35 measurements (SD 2.89) with a median of 2 measurements $(\mathrm{Q} 1=1$; $\mathrm{Q} 3=5)$ measurements per patient, respectively. The maximum number of time measurements per patient was 21 in the StatLock group and 16 in the SecurAcath group.

In the StatLock group, the geometric mean time needed per dressing change (StatLock change included) was $7.3 \mathrm{~min}$ (95\% CI 6.4 to 8.3) and in the SecurAcath group 4.3 min (95\% CI 3.8 to 4.9$) \quad(\mathrm{P}<0.001)$. A boxplot shows the distribution of the time measurements in the SecurAcath versus StatLock group (see online supplementary figure 1, Boxplot time measurements). The time per procedure in the SecurAcath group was reduced with $41 \%$ (95\% CI $29 \%$ to $51 \%$ ).

\section{Migration, dislodgement, infection, pain and usability of securement device placement and removal}

Table 2 summarises the secondary outcomes. Nurses assessed catheter migration at each dressing change. They reported two cases of an external catheter part of $\geq 3 \mathrm{~cm}$ : $4 \mathrm{~cm}$ the second day after PICC placement in the StatLock group $(\mathrm{n}=1)$ versus $20 \mathrm{~cm}$ on the day after PICC placement in the SecurAcath group $(\mathrm{n}=1)(\mathrm{P}=1.00)$.

The reason for PICC removal is unknown in four cases in the StatLock group. Therefore calculations regarding PICC removal are performed on 47 instead of 51 cases in the StatLock group. Dislodgement resulted in accidental PICC removal in 2 in 47 cases or 1.3/1000 catheter days (on the first and ninth day after PICC placement) in the StatLock and 3 in 51 cases or 1.9/1000 catheter days (on the 1st, 4th and 10th day after PICC placement) in the SecurAcath group $(\mathrm{P}=1.00)$.

Lab-confirmed CRBSI occurred in 2 in 47 cases in the StatLock group 34 and 84 days after PICC placement and in 1 in 51 cases in the SecurAcath group 29 days after PICG placement $(\mathrm{P}=1.00)$.

We found statistically significant differences between pain scores in the StatLock versus SecurAcath group at insertion $(\mathrm{P}=0.02)$ and at removal $(\mathrm{P}<0.001)$ but not for the total dwell time $(\mathrm{P}=0.99)$ or for pain scores during dressing change $(\mathrm{P}=0.29)$. In the SecurAcath group, pain at insertion and pain during dwell time were not related (Spearman rho $=-0.064, \mathrm{P}=0.69$ ), pain at insertion and at 
Open Access

Table 2 Secondary outcomes

\begin{tabular}{|c|c|c|c|}
\hline & StatLock & SecurAcath & $\mathbf{P}$ \\
\hline & $\mathrm{n}=161$ & $n=164$ & \\
\hline \multirow[t]{2}{*}{ Migration $(\geq 3 \mathrm{~cm})$ reported during dressing change } & $1(0.6 \%)$ & $1(0.6 \%)$ & 1.00 \\
\hline & $\mathrm{n}=47$ & $\mathrm{n}=51$ & \\
\hline Dislodgement resulting in PICC removal & $2(4.3 \%)$ & $3(5.9 \%)$ & 1.00 \\
\hline Confirmed CRBSI at PICC removal & $2(4.3 \%)$ & $1(2.0 \%)$ & 0.61 \\
\hline \multicolumn{4}{|l|}{ Pain } \\
\hline At insertion & $n=47$ & $\mathrm{n}=49$ & 0.02 \\
\hline None (NRS=0) & $44(93.6 \%)$ & $38(77.6 \%)$ & \\
\hline Mild (NRS $=1-2-3)$ & $3(6.4 \%)$ & $8(16.3 \%)$ & \\
\hline Moderate (NRS=4-5-6) & 0 & $2(4.1 \%)$ & \\
\hline Severe (NRS=7-8-9-10) & 0 & $1(2.1 \%)$ & \\
\hline During dressing change (highest reported score) & $n=43$ & $\mathrm{n}=48$ & 0.29 \\
\hline None (NRS=0) & $16(37.2 \%)$ & $20(41.7 \%)$ & \\
\hline Mild (NRS=1-2-3) & $22(51.2 \%)$ & $11(22.9 \%)$ & \\
\hline Moderate (NRS=4-5-6) & $5(11.6 \%)$ & $12(25.0 \%)$ & \\
\hline Severe (NRS=7-8-9-10) & 0 & $5(10.4 \%)$ & \\
\hline During dwell time & $n=31$ & $n=42$ & 0.995 \\
\hline None $(\mathrm{NRS}=0)$ & $19(61.3 \%)$ & $28(66.7 \%)$ & \\
\hline Mild (NRS $=1-2-3$ ) & $12(38.7 \%)$ & $11(26.2 \%)$ & \\
\hline Moderate (NRS=4-5-6) & 0 & $2(4.8 \%)$ & \\
\hline Severe (NRS=7-8-9-10) & 0 & $1(2.4 \%)$ & \\
\hline At removal & $n=25$ & $\mathrm{n}=44$ & $<0.001$ \\
\hline None (NRS=0) & $19(76.0 \%)$ & $20(45.5 \%)$ & \\
\hline Mild (NRS=1-2-3) & $6(24.0 \%)$ & $10(22.7 \%)$ & \\
\hline Moderate (NRS=4-5-6) & 0 & $11(25.0 \%)$ & \\
\hline Severe (NRS=7-8-9-10) & 0 & $3(6.8 \%)$ & \\
\hline Corresponding score for evaluation of the device at insertion* & $n=47$ & $\mathrm{n}=50$ & \\
\hline \multicolumn{4}{|l|}{ I find the device user-friendly to place } \\
\hline Mean (SD) & $4.5(0.6)$ & $3.4(1.0)$ & $<0.001$ \\
\hline Median (Q1-Q3) & $5.0(4.0-5.0)$ & $3.0(3.0-4.0)$ & \\
\hline \multicolumn{4}{|l|}{ I have no difficulties to place the device } \\
\hline Mean (SD) & $4.5(0.6)$ & $3.6(0.9)$ & $<0.001$ \\
\hline Median (Q1-Q3) & $5.0(4.0-5.0)$ & $4.0(3.0-4.0)$ & \\
\hline \multicolumn{4}{|l|}{ I prefer this device type } \\
\hline Mean (SD) & $4.0(0.9)$ & $3.1(0.8)$ & $<0.001$ \\
\hline Median (Q1-Q3) & $4.0(3.0-5.0)$ & $3.0(3.0-3.0)$ & \\
\hline \multicolumn{4}{|l|}{ I recommend this device type to use systematically } \\
\hline Mean (SD) & $3.9(0.8)$ & $3.0(0.6)$ & $<0.001$ \\
\hline Median (Q1-Q3) & $4.0(3.0-5.0)$ & $3.0(3.0-3.0)$ & \\
\hline Corresponding score for evaluation of the device at removal ${ }^{*}$ & $n=32$ & $\mathrm{n}=44$ & \\
\hline \multicolumn{4}{|l|}{ I find the device user-friendly to remove } \\
\hline Mean (SD) & $4.3(0.7)$ & $3.6(1.0)$ & $<0.001$ \\
\hline Median (Q1-Q3) & $5.0(4.0-5.0)$ & $4.0(3.0-4.0)$ & \\
\hline \multicolumn{4}{|l|}{ I have no difficulties to remove the device } \\
\hline Mean (SD) & $4.7(0.7)$ & $3.7(1.0)$ & $<0.001$ \\
\hline Median (Q1-Q3) & $5.0(5.0-5.0)$ & $4.0(3.0-4.0)$ & \\
\hline
\end{tabular}

Continued 
Table 2 Continued

\begin{tabular}{|c|c|c|c|}
\hline & StatLock & SecurAcath & $\mathbf{P}$ \\
\hline \multicolumn{4}{|c|}{ I prefer this device type } \\
\hline Mean (SD) & $3.1(0.7)$ & $3.6(0.9)$ & 0.004 \\
\hline \multicolumn{4}{|c|}{ I recommend this device type to use systematically } \\
\hline Mean (SD) & $3.3(0.9)$ & $3.6(0.9)$ & 0.32 \\
\hline
\end{tabular}

*1: strongly disagree; 2: disagree; 3: neutral; 4: agree; 5: strongly agree; nominal variables are analysed using a Fishers Exact test and ordinal variables using a Mann-Whitney $U$ test.

CRBSI, catheter-related bloodstream infection; NRS, Numerical Rating Scale; PICC, peripherally inserted central catheter.

removal were statistically significantly related (Spearman rho $=0.316, \mathrm{P}=0.04$ ). Overall, the usability of StatLock was evaluated statistically significantly more positive than SecurAcath at insertion and removal. At insertion, radiologists agreed to strongly agreed that the StatLock was user-friendly (mean score 4.5 ) and was without difficulties to place (mean score 4.5 ), while the SecurAcath was rated more neutrally regarding user-friendliness (mean score 3.4) and regarding difficulties when placing the device (mean score 3.6). Inserters agreed also that they would prefer (mean score 4.0) and would recommend (mean score 3.9) StatLock for PICC securement. Inserters were neutral regarding the preference of SecurAcath (mean score 3.1) and whether they would recommend (mean score 3.0) it when inserting PICCs. Nurses and physicians who removed the PICCs agreed with the statement that the StatLock is user-friendly (mean score 4.3) and may be removed without difficulties (mean score 4.7). Healthcare workers tended to agree that SecurAcath is user-friendly (mean score 3.6) and may be removed without difficulties (mean score 3.7). They were neutral in the preference (mean score 3.1) and the recommendation (mean score 3.3 ) of StatLock and tended to agree to prefer (mean score 3.6) and recommend (mean score 3.6) SecurAcath.

\begin{tabular}{|llll}
\hline Table 3 & Problems during dressing change & \\
\hline & $\begin{array}{l}\text { StatLock } \\
(\mathbf{n = 1 6 1 )} \\
\mathbf{n}(\%)\end{array}$ & $\begin{array}{l}\text { SecurAcath } \\
(\mathbf{n}=164) \\
\mathbf{n}(\%)\end{array}$ & $\mathbf{P}$ \\
\hline None & $99(61.5)$ & $108(65.9)$ & 0.53 \\
\hline Bleeding/oozing/haematoma & $21(13.0)$ & $24(14.6)$ & \\
\hline Pain at exit site & $16(9.9)$ & $17(10.4)$ & \\
\hline Signs of exit site infection & $10(6.2)$ & $7(4.3)$ \\
\hline $\begin{array}{l}\text { Medical adhesive-related skin } \\
\text { injuries }\end{array}$ & $6(3.7)$ & $7(4.3)$ \\
\hline Catheter migration $(\geq 3 \mathrm{~cm})$ & $1(0.6)$ & $1(0.6)$ \\
\hline Leakage and loose dressing & $5(3.1)$ & 0 \\
Other & $3(1.9)$ & 0 \\
\hline
\end{tabular}

$P$ values from logistic regression with generalised estimating equations.

\section{Adverse events}

Table 3 summarises the adverse events reported during dressing change. No adverse events were reported during dressing changes in $61.5 \%$ in the StatLock group and in $65.9 \%$ in the SecurAcath group. Both groups were comparable regarding the number of adverse event reports $(\mathrm{P}=0.53)$.

Clinical signs of bleeding, oozing or a haematoma at the exit site were reported in 13\% and $14.6 \%$ of dressing changes in the StatLock group and SecurAcath group, respectively. Explicitly pain reports without mentioning any other complication were similar in both groups. MARSI was reported comparable in both groups.

In one patient in the StatLock group, leakage via exit site, with or without mentioning of a loose dressing, was reported during five dressing changes.

Both groups were comparable regarding the number of days between reported dressing changes. The mean number of days between dressing changes was 6.8 (SD 6.0) in the StatLock group and 7.0 (SD 7.5) in the SecurAcath group.

\section{End of study reasons}

The reasons for the end of study are listed in table 4 . In four cases in the StatLock group, the reason for removal was unknown. PICCs were prematurely removed due to one specific complication in $21.3 \%$ of cases $(n=10)$ in the StatLock group and in $21.6 \%$ of cases $(n=11)$ in the SecurAcath group.

Difficulties in removing the SecurAcath were reported in 15 in 44 cases $(34 \%)$. A local anaesthetic with lidocaine (Linisol 2\%) was used seven times for the following reasons: difficult removal $(n=4)$, removal 1 day after insertion $(n=1)$, removal after several attempts by an inexperienced nurse $(n=1)$ and unknown $(n=1)$. In $71.8 \%$ of cases $(n=28)$, the SecurAcath was cut in two just before removal.

Patients stated to choose for the same securement device in $88.5 \%(n=23)$ and $82.5 \%(n=33)$ of cases in the StatLock and in the SecurAcath group, respectively. The following reasons for disapproval were given in the StatLock group: too frequent device changes $(n=1)$ and MARSI $(n=1)$, and in the SecurAcath group: too painful $(n=4)$ and causing a feeling of a burden $(n=1)$. 


\begin{tabular}{llll}
\hline Table 4 Reason for end of study & & \\
\hline & $\begin{array}{l}\text { StatLock } \\
(\mathbf{n}=\mathbf{4 7})\end{array}$ & $\begin{array}{l}\text { SecurAcath } \\
(\mathbf{n = 5 1 )}\end{array}$ & $\mathbf{P}$ \\
\hline PICC removed & & \\
\hline $\begin{array}{l}\text { End of intravenous therapy } \\
\text { Elective exchange for }\end{array}$ & $1(2.1 \%)$ & 0 & 0.48 \\
tunnelled catheter & $2(4.3 \%)$ & $1(2.0 \%)$ & 0.61 \\
Confirmed CRBSI & $3(6.4 \%)$ & $6(11.8 \%)$ & 0.49 \\
\hline $\begin{array}{l}\text { Suspected CRBSI } \\
\text { Dislodgement }\end{array}$ & $2(4.3 \%)$ & $3(5.9 \%)$ & 1.00 \\
\hline Catheter malfunction & $3(6.4 \%)$ & $1(2.0 \%)$ & 0.35
\end{tabular}

PICC in situ

\begin{tabular}{llll} 
Patient withdraw consent $\dagger$ & $1(2.1 \%)$ & 0 & 0.48 \\
$\begin{array}{l}\text { End of study time period } \\
\text { (>180 days) }\end{array}$ & 0 & $1(2.0 \%)$ & 1.00 \\
Patient deceased & $4(8.5 \%)$ & $4(7.8 \%)$ & 1.00 \\
\hline
\end{tabular}

$P$ values from Fisher's exact test.

${ }^{*}$ In four cases, the reason for removal was unknown. †Unrelated to the securement device use.

CRBSI, catheter-related bloodstream infection; PICC, peripherally inserted central catheter.

\section{DISCUSSION}

This study was based on the assertion that the change of the StatLock device is a time-consuming and potentially risky procedure creating stress for patients and nurses. Therefore, we wanted to test the hypothesis that the time for dressing change is reduced when using a securement device that does not need changing during weekly exit site care. Indeed, we found a mean reduction in time of 3 min per dressing change procedure in the SecurAcath group compared with the StatLock group $(\mathrm{P}<0.001)$.

The ultimate goal of a securement device is: (1) to secure the catheter to prevent catheter migration and dislodgement (2) to add no CRBSI risk, (3) to be painless and (4) to be user-friendly to handle. First, catheter migration was reported at dressing change once in both groups. In the SecurAcath group, the migration of $20 \mathrm{~cm}$ could be attributed to an incomplete closing of the SecurAcath lid. Although we found six more migration reports, four patients in the SecurAcath group $(3 \mathrm{~cm}(\mathrm{n}=3)$ and $13 \mathrm{~cm}$ $(\mathrm{n}=1)$ ) and two patients in the StatLock group (once $3 \mathrm{~cm}$ and once $10 \mathrm{~cm}$ ), we assume an incorrect measurement in all these cases. Indeed, the following external catheter length report at dressing change in the same patients did not report any migration anymore. Moreover, in the $13 \mathrm{~cm}$-migration case, a chest X-ray confirmed correct tip placement. Prevention of accidental catheter dislodgement is a real clinical challenge. In our study, three in five patients with catheter dislodgement were disorientated, the fourth patient reported that the incident occurred during the night. Finally, in the fifth patient, leakage (no blood) via the exit site loosened the catheter dressing and also the StatLock. The $5.9 \%$ dislodgement with SecurAcath is in line with the $7.4 \%$ of patients that removed their own catheter $(n=4)$ or had a dislodged catheter $(n=1)$ despite SecurAcath securement in the study of Egan and colleagues. ${ }^{6}$ However, the $4.6 \%$ of dislodgement we found with StatLock is lower than the $6.1 \%-12 \%$ in adults ${ }^{17}$ and $30.8 \%$ in paediatrics ${ }^{8}$ reported in other series.

Second, the incidence of confirmed CRBSI is low (0.6 per 1000 catheter days) for SecurAcath compared with 1.5/1000 catheter days in a previous study with SecurAcath. ${ }^{6}$

Third, we learnt that pain is a concern when using SecurAcath. We found higher pain scores with SecurAcath than with StatLock at insertion and removal. From our own pilot trial of 70 devices (unpublished data), we learnt that at insertion, the SecurAcath has to be placed deeply enough to avoid pain and that removal requires a certain force and dexterity. In our current RCT, none of the SecurAcath devices required premature removal due to pain. Nonetheless, a local anaesthetic is always used at PICC insertion and could also be considered at removal of a SecurAcath. ${ }^{9}$ We found a mean NRS score of $1.0 \pm 1.8$ for SecurAcath during PICC dwell time which is comparable with the $0.7 \pm 1.6$ as previously reported. ${ }^{6}$ The mean NRS score of $2.1 \pm 2.5$ at removal was slightly higher than the $1.5 \pm 2.5$ reported in Egan's study. ${ }^{6}$ However, patients reported the highest pain scores after dressing changes in both groups. It was clear from the free comments on the registration forms that patients, in both groups, included in their pain score the experienced pain during removal of the TSM dressing. MARSI reports were similar in the two groups: $3.7 \%$ in the StatLock and 4.3\% SecurAcath group. Moreover, MARSI observation along the TSM dressing surface was explicitly documented in $74 \%$ of MARSI reports and no indication was found to MARSI limited to neither the StatLock nor the SecurAcath zone. Therefore, we conclude that MARSI is a minor adverse event unrelated to both types of securement device.

Fourth, we found that the SecurAcath was considered statistically significantly less user-friendly than the StatLock. Indeed, this could be explained by the learning curve for placement and removal of SecurAcath. However, at removal, no difference was found between the two devices regarding the recommendation to use the device systematically. An explanation could be that nurses mostly removed the system. Potentially, they recall the drawbacks of both systems such as the weekly change for StatLock and the more difficult removal of SecurAcath, when scoring the recommendation to use the securement device systematically. So both systems have their advantages and disadvantages and at removal healthcare workers considered neither system ideal.

We conclude that the use of SecurAcath is safe regarding migration, dislodgement and CRBSI; still, pain could be maximally avoided by training the users.

Our study has some methodological limitations which might affect the generalisability of the trial findings. First, we included only $31 \%$ of eligible patients mainly because at the moment of PICC insertion, patients were unable to sign the ICF which might be explained by the setting of 
a tertiary care hospital. Though we presume no impact on our primary outcome, the needed time for dressing change, because we assume a difference in time if you need to change the securement device or not, independent of, for example, the patient's condition or the ability to speak Dutch. We expect that nurses working in a teaching hospital are more experienced in the use of both securement devices. If so, the dressing change time will be, especially in the StatLock group due to the difficult manipulation, lower than expected in the general population. So, potentially, the effect size might be larger in the general population. Second, the analysis sample for the primary outcome contained only 92 patients despite we randomised 105 patients. However, this was compensated by patients having multiple measurements while the sample size was calculated based on a minimum of one measurement per patient. More specifically, with 3.5 as the mean number of dressing change measurements and 0.29 as the correlation between the multiple dressing change measurements from the same patient, the design effect equalled 1.725. Applying this inflation factor on the original sample size calculation at least $176(=102 * 1.725)$ dressing change measurements in total were required to guarantee the desired power level of $80 \%$. We have further clarified the issue of missing data in 3/52 and $10 / 53$ of the patients randomised to the SecurAcath and StatLock group, respectively. Although not being statistically significant $(\mathrm{P}=0.073)$, we added a sensitivity analysis to study the potential impact on the drawn conclusion for the primary outcome. To obtain a non-statistically significant difference between both groups, the time needed for dressing change for patients with missing data would have been at least 2.8 times longer for the three patients in the SecurAcath group compared with the 10 patients in the StatLock group. Since this is highly unlikely, we can safely conclude that the obtained finding on the primary outcome is robust with respect to the presence of missing data. Additional information on sensitivity analysis may be found in online supplementary files and is illustrated in online supplementary figure 2, Sensitivity Analysis. Third, we also missed data at removal, especially in the StatLock group, because these PICCs could be easily removed by staff nurses while in the SecurAcath group, nurses of the vascular access team involved in the study removed most of the PICCs. However, we assume limited bias in the usability results because StatLock is not associated with difficulties at removal. We observed higher pain scores at removal within the SecurAcath group. A possible explanation could be that in this group not all devices were removed by the experienced APN from the vascular access team, as intended. However, in a posthoc analysis, we found no difference in pain scores as a function of the experience of the clinician within the SecurAcath group.

Finally, we did not perform a full economic assessment of the use of both devices. Nevertheless, the reduced needed nursing time for dressing change with StatLock should be taken into account in further financial evaluations. Further research should focus on strategies to reduce pain associated with SecurAcath and also with TSM dressing's removal. Additionally, the ease of SecurAcath removal after a long dwell time should be further investigated because in our study, the follow-up time was limited to 180 days.

SecurAcath is a valuable and safe alternative for StatLock. However, knowledge and training for precise placement, for smooth handling during dressing change and for a correct removal of the device, are critical.

\section{CONCLUSION}

We compared two devices for PICC securement, namely StatLock which has to be changed weekly, and SecurAcath which remains in place for the complete PICC dwell time. We found a statistically significant reduced time for the dressing change. In the development of new technologies, the potential of reducing nursing procedural time is an important factor given the nursing shortage.

\section{Author affiliations}

${ }^{1}$ Nursing Centre of Excellence, University Hospitals Leuven, Leuven, Belgium ${ }^{2}$ Department of Public Health and Primary Care, KU Leuven, Leuven, Belgium ${ }^{3}$ Department of Nephrology, University Hospitals Leuven, Leuven, Belgium ${ }^{4}$ Interuniversity Centre for Biostatistics and Statistical Bioinformatics, KU Leuven, Leuven and Universiteit Hasselt, Leuven, Belgium

${ }^{5}$ Institute of Health and Care Sciences, University of Gothenburg, Gothenburg, Sweden

${ }^{6}$ Surgical Oncology, University Hospitals Leuven, Leuven, Belgium ${ }^{7}$ Interventional Radiology, University Hospitals Leuven, Leuven, Belgium

Acknowledgements We want to thank Dr W E Peetermans for reviewing CRBSI in our study patients.

Collaborators Veerle Boecxstaens, Lawrence Bonne, Kathleen Claes, Steve Coppens, Katrien Cosaert, VeerleCossey, Sophie Detailleur, Yves Debaveye, Inge Derdelinckx, Daan Dierckx, Christophe Dooms, Inge Fourneau, Christiaan Franz, Godelieve Goossens, Greetje Hendriks, Greet Hermans,Daphne Hompes, Christel Janssens, Martine Jérôme, Geert Maleux, Philippe Meersseman, Djalila Mekahli, Paola Melussi, Willy Peetermans, Marc Persoons, Hans Prenen, Marleen Renard, Marguerite Stas, Ester Steffens, Christel Stuyven, Els Van Der Mynsbrugge, Lucia Van Roy, Nancy Vansteenkiste, Hans Wildiers

Contributors GAG, NG: contributions to conception and design, literature search acquisition of data, data interpretation, writing, final approval of the version to be published. CJ, MJ, GM: contributions to conception and design, acquisition of data, data interpretation, writing, final approval of the version to be published. SF: contributions to conception and design, data analysis and interpretation, writing, final approval of the version to be published. PM: contributions to conception and design, data interpretation, writing, final approval of the version to be published. MS: data interpretation, writing, final approval of the version to be published.

Funding This research received no specific grant from any funding agency in the public, commercial or not-for-profit sectors.

Competing interests None declared.

Patient consent Obtained.

Ethics approval The study protocol was approved by hospitals local Ethics Committee (\$57358), and the trial was registered at clinicaltrials.gov (NCT02311127).

Provenance and peer review Not commissioned; externally peer reviewed.

Data sharing statement All available data can be obtained from the corresponding author.

Open Access This is an Open Access article distributed in accordance with the Creative Commons Attribution Non Commercial (CC BY-NC 4.0) license, which permits others to distribute, remix, adapt, build upon this work non-commercially, and license their derivative works on different terms, provided the original work is 
properly cited and the use is non-commercial. See: http://creativecommons.org/ licenses/by-nc/4.0/

(C) Article author(s) (or their employer(s) unless otherwise stated in the text of the article) 2018. All rights reserved. No commercial use is permitted unless otherwise expressly granted.

\section{REFERENCES}

1. Yamamoto AJ, Solomon JA, Soulen MC, et al. Sutureless securement device reduces complications of peripherally inserted central venous catheters. J Vasc Interv Radiol 2002;13:77-81.

2. Ullman AJ, Cooke ML, Mitchell M, et al. Dressing and securement for central venous access devices (CVADs): A Cochrane systematic review. Int J Nurs Stud 2016;59:177-96.

3. Macklin D, Blackburn PL. Central venous catheter securement: using the healthcare and technology synergy model to take a closer look. JAVA 2015;20:45-50.
4. Jones TL, Schlegel C. Can real time location system technology (RTLS) provide useful estimates of time use by nursing personnel? Res Nurs Health 2014;37:75-84.

5. Horan TC, Andrus M, Dudeck MA. CDC/NHSN surveillance definition of health care-associated infection and criteria for specific types of infections in the acute care setting. Am J Infect Control 2008;36:309-32.

6. Egan GM, Siskin GP, Weinmann R, et al. A prospective postmarket study to evaluate the safety and efficacy of a new peripherally inserted central catheter stabilization system. J Infus Nurs 2013;36:181-8.

7. Valbousquet Schneider L, Duron S, Arnaud FX, et al. Evaluation of PICC complications in orthopedic inpatients with bone infection for long-term intravenous antibiotics therapy. $J$ Vasc Access 2015;16:299-308.

8. Waterhouse J, Bandisode V, Brandon D, et al. Evaluation of the use of a stabilization device to improve the quality of care in patients with peripherally inserted central catheters. AACN Adv Crit Care 2014;25:213-20.

9. Elen Hughes M. Reducing PICC migrations and improving patient outcomes. Br J Nurs 2014;23:S12, S14-18. 